\title{
Uneven chances of breastfeeding in Spain
}

\author{
Isabel Río ${ }^{1 *}$, Álvaro Luque ${ }^{2}$, Adela Castelló-Pastor ${ }^{1}$, María del Val Sandín-Vázquez ${ }^{3}$, Rosana Larraz³, \\ Carmen Barona ${ }^{4,5}$, Mireia Jané ${ }^{6}$ and Francisco Bolúmar ${ }^{3,5}$
}

\begin{abstract}
Background: No large scale studies on breastfeeding onset patterns have been carried out in Spain. This work aims to explore the prevalence and the risk factors for not initiating breastfeeding in hospitals from Catalonia (CAT) and Valencia (V), two regions accounting approximately for 30\% of the annual births in Spain.

Methods: The prevalence of not initiating breastfeeding was calculated by maternal/neonatal characteristics and type of hospital, and logistic regression models were used to estimate crude and adjusted risks of not breastfeeding in each region.

Results: Prevalence of breastfeeding initiation was $81.7 \%$ and $82.5 \%$ in Catalonia and Valencia, respectively. We identified conspicuous regional differences in the adjusted-risk of not breastfeeding, especially for multiple [CAT= 3.12 (95\% Cl: 2.93, 3.31), $\mathrm{V}=2.44$ (95\% Cl: $2.23,2.67)$ ] and preterm and low birth weight deliveries [very preterm and very low birth weight: $\mathrm{CAT}=7.61$ (95\% Cl: $6.50,8.92), \mathrm{V}=4.03$ (95\% Cl: 3.13, 5.19); moderate preterm and moderate low birth weight: CAT $=4.28$ (95\% Cl: 4.01, 4.57), $\mathrm{V}=2.55$ (95\% Cl:2.34, 2.79)].

Conclusions: Our results suggest the existence of regional variations in breastfeeding initiation in Spain. Taking into account the known short and long-term benefits of breastfeeding it is recommended that further research should explore these differences in order to prevent potential inequities in neonatal, child and adult health.
\end{abstract}

Keywords: Feeding behavior, Perinatal care, Quality of health care, Determinants of breastfeeding, Method of birth

\section{Background}

There is strong evidence on the short and long-term benefits of breastfeeding for the health of newborns. International institutions prompt the need of monitoring newborn's nutrition trends and to promote early initiation of breastfeeding and continuation of breastfeeding during the first six months of life. A nation-wide registry of breastfeeding patterns does not yet exist in Spain. In 2006, the latest National Survey of Health showed that the estimated prevalence of breastfeeding in children from 6 months to 4 years was $68.4 \%$ at 6 weeks after birth and $52.48 \%$ and $24.72 \%$ at 3 and 6 months, respectively [1]. No large scale studies on the patterns and determinants of breastfeeding onset in hospital have been carried out in the country. Here we investigate the prevalence and the risk factors for not initiating breastfeeding in two Spanish regions.

\footnotetext{
* Correspondence: isario@isciii.es

${ }^{1}$ National Centre of Epidemiology, Institute of Health Carlos III, Madrid, Spain Full list of author information is available at the end of the article
}

\section{Methods}

A cross-sectional study was carried out using data of births in 2005 and 2006 provided by the regional registries of metabolic disorders from Catalonia and Valencia (Figure 1), two Spanish regions accounting approximately for $30 \%$ of the total annual births in the country. These registries record information on childbirths (universal coverage) supplied by all public and private hospitals in each region. In addition to the information on metabolic disorders in the newborns they also record the type of nourishment initiated in the first 24 hours after delivery (breastfeeding vs. artificial feeding). Such information provides the only source allowing for monitoring of regional patterns of breastfeeding initiation in Spain. Data about type (single vs. multiple) and mode (vaginal vs. Caesarean section) of delivery and type of hospital (public vs. private), as well as information on maternal age and country of origin, and newborn's characteristics such as sex, gestational age and birth weight are also registered.

We classified newborns into three categories according to the mother's age $(<20,20-34$ or $\geq 35$ years $)$ and in
C Biomed Central

(C) 2012 Rio et al.; licensee BioMed Central Ltd. This is an Open Access article distributed under the terms of the Creative Commons Attribution License (http://creativecommons.org/licenses/by/2.0), which permits unrestricted use, distribution, and reproduction in any medium, provided the original work is properly cited. 


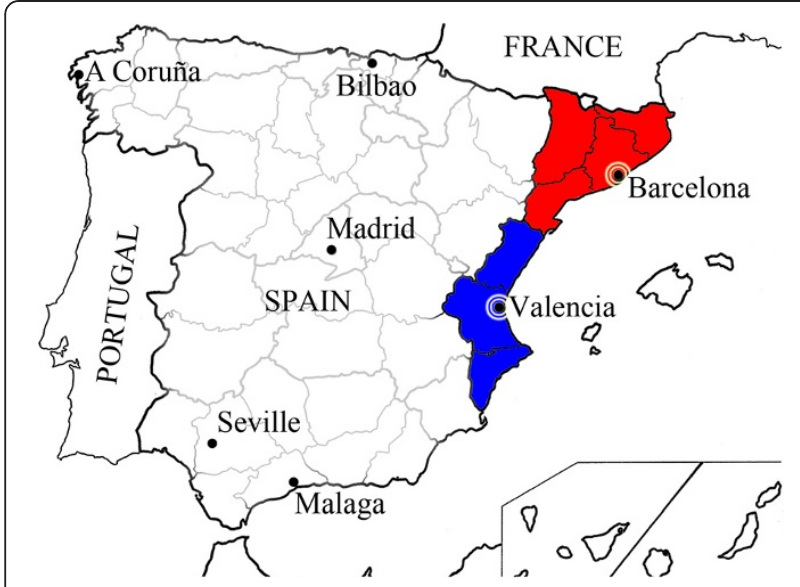

Figure 1 Map of Spain with Catalonia (red) and Valencia (blue) highlighted.

eight categories according to their region of origin (Spain, Latin-America, Maghreb, Eastern-Europe, Sub-Saharan Africa, North-Asia, South-Asia and "Other regions" which includes women belonging to countries in regions with minor representation in Spain). Regarding newborn's characteristics, we grouped both gestational age and birth weight into three categories (very preterm (VPTB): $<32$ weeks, moderate preterm (MPTB): 32-36 weeks, and at term: $\geq 37$ weeks) and (very low birth weight (VLBW): $<1500$ gr., moderate low birth weight (MLBW): 1500-2499, and normal weight: $\geq 2500$ gr.). Percentages of not initiating breastfeeding by maternal and neonatal characteristics and by type of hospital were calculated for each one of the regions and compared using chi-square tests. Multiple logistic regression models were used to estimate crude and adjusted risk (odds ratios and 95\% confidence intervals) of not initiating breastfeeding in each region. In order to estimate these risks for the most common adverse reproductive outcomes a variable combining birth weight and gestational age data was created and newborns classified into seven categories (VPTB but not VLBW, VLBW but not VPTB, VPTB and VLBW, MPTB with normal weight, MLBW with normal gestational age, MPTB and MLBW and normal gestational age and weight at birth). Analyses were carried out with the SPSS software version 17.0.

\section{Results}

The number of registered births were $260,465,62.4 \%$ of them in Catalonia and $37.6 \%$ in Valencia. Information on type of feeding was missing for $0.4 \%$ of births in Catalonia and $6.1 \%$ of births in Valencia. The total number of births and percentages by neonatal and maternal characteristics and type of hospital in each region are showed in Table 1. As expected, single and vaginal deliveries of 20-34 years old women in public hospitals and newborns at term and with normal weight were the most frequently reported. However, inter-regional comparisons showed a higher frequency of multiple deliveries and Caesarean sections in Catalonia than in Valencia, as well as a higher proportion of deliveries from immigrant women and deliveries in private hospitals. In contrast, percentages of prematurity and low birth weight were higher in Valencia than in Catalonia, as well as

Table 1 Births in two Spanish regions by neonatal/ maternal characteristics and type of hospital

\begin{tabular}{|c|c|c|}
\hline & Catalonia & Valencia \\
\hline & n (\%) & n (\%) \\
\hline \multicolumn{3}{|l|}{ Type of delivery } \\
\hline Single & $144898(95.9)$ & $94688(96.7)$ \\
\hline Multiple & $6269(4.1)$ & 3275 (3.3) \\
\hline \multicolumn{3}{|l|}{ Mode of delivery } \\
\hline Vaginal & $111915(71.5)$ & $72593(74.8)$ \\
\hline Caesarean section & $44588(28.5)$ & $24475(25.2)$ \\
\hline \multicolumn{3}{|l|}{ Sex } \\
\hline Male & $82705(51.7)$ & $45999(51.3)$ \\
\hline Female & $77396(48.3)$ & $43679(48.7)$ \\
\hline \multicolumn{3}{|c|}{ Gestational age (weeks) } \\
\hline VPTB $(<32)$ & $1329(0.8)$ & $697(0.7)$ \\
\hline MPTB (32-36) & $10400(6.6)$ & $7325(7.8)$ \\
\hline At Term ( $\geq 37)$ & $146355(92.6)$ & $85430(91.4)$ \\
\hline \multicolumn{3}{|l|}{ Birthweight (grams) } \\
\hline VLBW $(<1500)$ & $1237(0.8)$ & $646(0.7)$ \\
\hline MLBW (1500-2499) & $10781(6.6)$ & $6931(7.3)$ \\
\hline Normal ( $\geq 2500)$ & $150131(92.6)$ & $87755(92.1)$ \\
\hline \multicolumn{3}{|l|}{ Maternal age (years) } \\
\hline$<20$ & $3269(2.1)$ & $1985(2.4)$ \\
\hline $20-34$ & $117436(74.3)$ & $59702(71.0)$ \\
\hline$\geq 35$ & $37325(23.6)$ & $22407(26.6)$ \\
\hline \multicolumn{3}{|l|}{ Maternal origin } \\
\hline Spain & $117760(72.5)$ & $74185(75.7)$ \\
\hline Latin-America & $11869(7.3)$ & $5332(5.4)$ \\
\hline Maghreb & $9921(6.1)$ & $2544(2.8)$ \\
\hline Eastern-Europe & $3366(2.1)$ & $3588(3.7)$ \\
\hline Sub-Saharan Africa & $1830(1.1)$ & $487(0.5)$ \\
\hline North-Asia & $1718(1.1)$ & $441(0.5)$ \\
\hline South-Asia & $1287(0.8)$ & $160(0.2)$ \\
\hline Other regions & $2707(1.7)$ & $1776(1.8)$ \\
\hline \multicolumn{3}{|l|}{ Type of hospital } \\
\hline Public & $115557(71.1)$ & $86858(89.5)$ \\
\hline Private & $46945(28.9)$ & $10141(10.5)$ \\
\hline \multicolumn{3}{|l|}{ Breastfeeding } \\
\hline Yes & $132699(81.7)$ & $80835(82.5)$ \\
\hline No & $29803(18.3)$ & $17128(17.5)$ \\
\hline
\end{tabular}


higher percentages of deliveries from older mothers. Overall, the lack of breastfeeding initiation was slightly higher in Catalonia (18.3\% vs. $17.5 \%$ ).

Tables 2 and 3 shown, respectively, percentages and crude and adjusted risks of not initiating breastfeeding by maternal and neonatal characteristics and by type of hospital. A remarkable variability between regions was observed regarding the risk of not breastfeeding after multiple delivery or Caesarean section and also for preterm and low weight births. Thus, while the adjusted risk of not breastfeeding for women with multiple pregnancies was 2.44 (95\% CI: 2.23, 2.67) in Valencia, this risk increased to 3.12 (95\% CI: 2.93, 3.31) in Catalonia. The comparison of different levels of prematurity or low birth weight showed a finely graded association with breastfeeding in both regions, the more adverse reproductive outcome the higher the risk of not initiating breastfeeding, but these risks were always higher in Catalonia. Thus, while in Valencia the risk of not breastfeeding for MPTB or MLBW babies was 51\% higher than for those at term and with normal birth weight $[\mathrm{OR}=1.51 \quad(95 \% \mathrm{CI}: 1.40,1.61)]$, it was doubled in Catalonia $[\mathrm{OR}=2.00$ (95\% CI: $1.90,2.11)]$. Newborns with both conditions had a 2.55 (95\% CI:2.34, 2.79)

Table 2 Intra- and inter-regional comparisons of the percentages of not breastfeeding onset by neonatal/maternal characteristics and type of hospital

\begin{tabular}{|c|c|c|c|c|c|}
\hline & & & & & 2 Regions comparison \\
\hline & n (\%) & $p$-value ${ }^{a}$ & n (\%) & $p$-value ${ }^{a}$ & p-value ${ }^{a}$ \\
\hline Type of delivery & & $<0.0001$ & & $<0.0001$ & \\
\hline Single & $24060(16.6)$ & & $15435(16.3)$ & & 0.050 \\
\hline Multiple & $3594(57.3)$ & & $1693(51.7)$ & & $<0.0001$ \\
\hline Mode of delivery & & $<0.0001$ & & $<0.0001$ & \\
\hline Vaginal & $17940(16.0)$ & & $9787(13.5)$ & & $<0.0001$ \\
\hline Caesarean section & $10957(24.6)$ & & $7098(29.0)$ & & $<0.0001$ \\
\hline$\overline{\text { Sex }}$ & & 0.428 & & 0.081 & \\
\hline Male & $15254(18.4)$ & & $7706(16.8)$ & & $<0.0001$ \\
\hline Female & $14156(18.3)$ & & $7128(16.3)$ & & $<0.0001$ \\
\hline Gestational age (weeks) & & $<0.0001$ & & $<0.0001$ & \\
\hline VPTB $(<32)$ & $762(57.8)$ & & $347(49.8)$ & & $<0.0001$ \\
\hline MPTB (32-36) & $4511(43.4)$ & & $2528(34.5)$ & & $<0.0001$ \\
\hline At Term $(\geq 37)$ & $23698(16.2)$ & & $13443(15.7)$ & & 0.202 \\
\hline Birthweight (grams) & & $<0.0001$ & & $<0.0001$ & \\
\hline VLBW $(<1500)$ & $797(64.4)$ & & $331(51.2)$ & & $<0.0001$ \\
\hline MLBW (1500-2499) & $4961(46.0)$ & & $2495(36.0)$ & & $<0.0001$ \\
\hline Normal $(\geq 2500)$ & $23978(16.0)$ & & $13778(15.7)$ & & 0.590 \\
\hline Maternal age (years) & & $<0.0001$ & & $<0.0001$ & \\
\hline$<20$ & $530(16.2)$ & & $329(16.6)$ & & 0.729 \\
\hline $20-34$ & $20650(17.6)$ & & $10041(16.8)$ & & $<0.0001$ \\
\hline$\geq 35$ & $7746(20.8)$ & & $4564(20.4)$ & & 0.264 \\
\hline Maternal origin & & $<0.0001$ & & $<0.0001$ & \\
\hline Spain & $23709(20.1)$ & & $14109(19.0)$ & & $<0.0001$ \\
\hline Latin-America & $1806(9.1)$ & & $316(5.9)$ & & $<0.0001$ \\
\hline Maghreb & $747(7.5)$ & & $149(5.9)$ & & 0.004 \\
\hline Eastern-Europe & $346(10.3)$ & & $321(8.9)$ & & 0.610 \\
\hline Sub-Saharan Africa & $149(8.1)$ & & $63(12.9)$ & & 0.002 \\
\hline North-Asia & $899(52.3)$ & & $217(49.2)$ & & 0.262 \\
\hline South-Asia & $174(13.5)$ & & $21(13.1)$ & & 1 \\
\hline Other regions & $335(12.4)$ & & $342(13.3)$ & & 0.260 \\
\hline Type of hospital & & $<0.0001$ & & $<0.0001$ & \\
\hline Public & $20271(17.5)$ & & $15052(17.3)$ & & 0.124 \\
\hline Private & $9532(20.3)$ & & $1899(18.7)$ & & $<0.0001$ \\
\hline
\end{tabular}

$\mathrm{a}=\mathrm{p}$-value $<0.05$. 
Table 3 Risk of not initiating breastfeeding in two Spanish regions by neonatal/maternal characteristics and type of hospital

\begin{tabular}{|c|c|c|c|c|}
\hline & \multicolumn{2}{|c|}{ Catalonia } & \multicolumn{2}{|c|}{ Valencia } \\
\hline & $\mathrm{ORc}^{\mathrm{a}}(\mathrm{Cl} 95 \%)$ & $\mathrm{ORa}^{\mathrm{b}}(\mathrm{Cl} 95 \%)$ & $\mathrm{ORc}^{\mathrm{a}}(\mathrm{Cl} 95 \%)$ & $\mathrm{ORa}^{\mathrm{b}}(\mathrm{Cl}$ 95\%) \\
\hline \multicolumn{5}{|l|}{ Type of delivery } \\
\hline Single & 1 & 1 & 1 & 1 \\
\hline Multiple & $6.75(6.41,7.11)$ & $3.12(2.93 .3 .31)$ & $5.50(5.12,5.90)$ & $2.44(2.23,2.67)$ \\
\hline \multicolumn{5}{|l|}{ Mode of delivery } \\
\hline Vaginal & 1 & 1 & 1 & 1 \\
\hline Caesarean section & $1.71(1.66,1.75)$ & $1.35(1.31,1.39)$ & $2.62(2.53,2.71)$ & $2.09(2.02,2.18)$ \\
\hline \multicolumn{5}{|l|}{ Gestational age/birth weight } \\
\hline$\geq 37$ weeks and $\geq 2500$ grs. & 1 & 1 & 1 & 1 \\
\hline MPTB or MLBW & $2.45(2.34,2,57)$ & $2.00(1.90,2.11)$ & $1.90(1.79,2.01)$ & $1.51(1.40,1.61)$ \\
\hline MPTB and MLBW & $6.63(6.27,7.01)$ & $4.28(4.01,4.57)$ & $4.10(3.83,4.38)$ & $2.55(2.34,2.79)$ \\
\hline VPTB or VLBW & $6.00(5.39,6.69)$ & $4.33(3.84,4.89)$ & $4.69(3.90,5.64)$ & $2.73(2.16,3.44)$ \\
\hline VPTB and VLBV & $10.37(8.99,11.96)$ & $7.61(6.50,8.92)$ & $6.29(5.19,7.62)$ & $4.03(3.13,5.19)$ \\
\hline \multicolumn{5}{|l|}{ Maternal age } \\
\hline$<20$ & $0.91(0.83,1.00)$ & $1.19(1.07,1.32)$ & $0.98(0.87,1.11)$ & $1.33(1.17,1.50)$ \\
\hline $20-34$ & 1 & 1 & 1 & 1 \\
\hline$\geq 35$ & $1.23(1.19,1.26)$ & $1.10(1.06,1.14)$ & $1.27(1.22,1.32)$ & $1.10(1.06,1.15)$ \\
\hline \multicolumn{5}{|l|}{ Maternal origin } \\
\hline Spain & 1 & 1 & 1 & 1 \\
\hline Latin-America & $0.40(0.38,0.43)$ & $0.41(0.38,0.44)$ & $0.27(0.24,0.30)$ & $0.26(0.23,0.29)$ \\
\hline Maghreb & $0.32(0.30,0.35)$ & $0.34(0.32,0.37)$ & $0.27(0.22,0.31)$ & $0.28(0.24,0.34)$ \\
\hline Eastern-Europe & $0.45(0.41,0.51)$ & $0.48(0.42,0.54)$ & $0.42(0.37,0.47)$ & $0.43(0.38,0.49)$ \\
\hline Sub-Saharan Africa & $0.35(0.30,0.42)$ & $0.36(0.30,0.43)$ & $0.63(0.49,0.83)$ & $0.55(0.41,0.73)$ \\
\hline North-Asia & $4.35(3.96,4.79)$ & $5.54(5.00,6.15)$ & $4.13(3.42,4.98)$ & $4.71(3.85,5.77)$ \\
\hline South-Asia & $0.62(0.53,0.73)$ & $0.60(0.50,0.71)$ & $0.64(0.41,1.02)$ & $0.60(0.36,0.98)$ \\
\hline Others & $0.56(0.50,0.63)$ & $0.90(0.84,0.96)$ & $0.86(0.81,0.91)$ & $1.11(0.99,1.24)$ \\
\hline \multicolumn{5}{|l|}{ Type of hospital } \\
\hline Public & 1 & 1 & 1 & 1 \\
\hline Private & $1.20(1.17,1.23)$ & $1.04(1.01,1.07)$ & $1.10(1.04,1.16)$ & $0.99(0.93,1.05)$ \\
\hline
\end{tabular}

$O R a^{b}=$ Odds Ratio Adjusted for all the other characteristics.

higher risk of not breastfeeding in Valencia. but a 4.28 (95\% CI:4.01, 4.57) higher risk in Catalonia. A similar pattern was identified for VPTB and VLBW neonates, with those presenting only one of these outcomes having a 2.73 (95\% CI: 2.16, 3.44) higher risk in Valencia but 4.33 (95\% CI: 3.84, 4.89) in Catalonia, and neonates with both conditions having the highest risk in both regions but, once again, clearly higher in Catalonia [OR $=7.61$ (95\% CI: 6.50, 8.92)] than in Valencia [OR $=4.03$ (95\% CI: $3.13,5.19)]$. The only factor leading to a higher risk of not initiating breastfeeding in Valencia than in Catalonia was the occurrence of a Caesarean section intervention, which increased $35 \%$ [OR $=1.35$ (95\% CI: 1.31, 1.39)] the risk of not initiating breastfeeding in Catalonia while doubling the risk in Valencia $[\mathrm{OR}=2.09$ (95\% CI: 2.02, 2.18)]. Regarding other characteristics such as age and geographical origin of the mothers, the adjusted risk was higher for younger and older women and also higher for native than for foreign-born women in both regions. The magnitude of this difference was higher in Catalonia than in Valencia although confidence intervals of the regional risk estimations often overlap.

\section{Discussion}

This is the first large scale population-based study on breastfeeding onset patterns in Spanish hospitals and one of the few providing specific estimates of breastfeeding in preterm and low birth weight babies in European 
countries [2]. Comparison of Catalonia and Valencia, two regions with a wide representation of the total births in the country, indicated a very marked variability in the magnitude of the risk of not initiating breastfeeding imposed for known postnatal nutrition determinants. This variability implies that mothers in Catalonia face greater obstacles in initiating breastfeeding than their counterparts in Valencia when they have multiple pregnancies or when their newborns are very or moderate preterm and/or they have a very or moderate low birth weight. In contrast, women delivering by Caesarean section found increased barriers to maternal breastfeeding in this last region. Inter-regional differences also confirm the better rates of breastfeeding initiation among immigrants compared to native women, with the exception of North-Asiatic mothers as described recently [3]. However, according to our analysis, this advantage seems slightly reduced among immigrant groups living in Catalonia.

The probability of initiating breastfeeding is a complex function of individual, social, cultural and clinical factors. Moreover, there is an obvious challenge to feeding most vulnerable infants. However, a marked variability in feeding practices of neonatal intensive care units has been reported indicating that, even under these circumstances, breastfeeding can successfully be established [4-6]. Poor guidelines on the importance of breastfeeding and lack of adequate professional training in breastfeeding promotion strategies as well as inadequate practices in maternities and neonatal intensive units have been proposed as barriers for optimal breastfeeding rates $[7,8]$.

Some caveats must be considered when evaluating the results presented here. Firstly, there are no validation studies of breastfeeding data reported by the registries of metabolic disorders and this represents an important limitation of our study. Secondly, registries do not provide information on a large number of factors associated with initiating breastfeeding and we cannot rule out their potential influences. Moreover, information about the type of feeding initiated in hospital is presented as a dichotomous variable and we cannot discriminate if regional differences identified here are on exclusive breastfeeding and/or mixed feeding. Finally, data collected in the registries refers to the type of feeding initiated during the next 24 hours after birth, which does not necessarily imply that newborns, especially very preterm and with very low weight at birth, have not started breastfeeding later before they leave the hospital. However, this possibility could equally affect both regions and would not explain inter-regional differences found here. We cannot rule out the putative influence of missing values in our results. In Valencia no information was available on the type of feeding provided to $6.1 \%$ of babies, while in Catalonia the missing values for this variable were only $0.4 \%$. As a strategy to evaluate the potential influence of missing values in our results, we repeated the statistical analysis under the strong assumption that all preterm and low weight births in Valencia with missed data about the type of nourishment (15.6\% and $13.7 \%$ of total cases with missing values for type of feeding) started artificial feeding. Despite a reduction in regional differences, the results of this second analysis (data not shown) indicated that even in this improbable scenario, estimates of risk still remain more favorable for very and moderate premature or low birth weight infants born in Valencia than for those born in Catalonia. Regarding the potential influence of missing values for other variables such as gestational age or birth weight, we confirm that the proportions of breastfeeding were consistent with our results. Thus, in Catalonia $19.0 \%$ of newborns without information on gestational age and $18.8 \%$ with unknown birth weight were not breastfed, while these percentages were $14.7 \%$ and $14.5 \%$ in Valencia, respectively. Therefore, we presume the validity of our results.

\section{Conclusions}

Our results suggest that further research on the regional differences on initiation of breastfeeding in Spain as well as on the differences in breastfeeding initiation in women having Caesarean or vaginal deliveries and VLBW babies is needed.

\section{Competing interests}

The authors declare that they have no competing interests.

\section{Authors' contributions}

IR designed the study. CB and MJ were responsible for the acquisition of initial data. ACP and AL performed the statistical analysis. IR wrote the first manuscript. RL, MVSV and FB collaborated in the interpretation of results and all co-authors revised critically the successive drafts and approved the final version of the article.

\section{Acknowledgements}

This work was supported in part by grants from the Spanish Ministry of Science and Innovation (CSO2011-26245) and the Spanish Network of Epidemiology and Public Health (CIBERESP). The sponsors were not involved in the study design, in the collection, analysis and interpretation of data; in the writing of the manuscript; and in the decision to submit the manuscript for publication.

\section{Author details}

National Centre of Epidemiology, Institute of Health Carlos III, Madrid, Spain. ${ }^{2}$ Faculty of Sciences, University of Alicante, Alicante, Spain. ${ }^{3}$ Department of Public Health Sciences, Faculty of Medicine, University of Alcalá, Madrid, Spain. ${ }^{4}$ Department of Health, General Directorate of Public Health, Generalitat Valenciana, Valencia, Spain. ${ }^{5}$ Division of Environmental and Reproductive Epidemiology, Spanish Network for Research in Epidemiology and Public Health (CIBERESP), Valencia, Spain. ${ }^{6}$ Department of Health, Mother and Child Health Program, General Directorate of Public Health, Barcelona, Catalonia, Spain.

Received: 23 April 2012 Accepted: 3 December 2012

Published: 27 December 2012

\section{References}

1. Spanish National Institute of Statistics: National health survey; 2006. Accesible in: http://www.ine.es/jaxi/menu.do?type = pcaxis\&path=/t15/ p419\&file $=$ inebase\& $=1$. 
2. Bonet M, Blondel B, Agostino R, Combier E, Maier RF, Cuttini M, Khoshnood $B$, Zeitlin J: Variations in breastfeeding rates for very preterm infants between regions and neonatal units in Europe: results from the MOSAIC cohort. Arch Dis Child Fetal Neonatal Ed 2011, 96:F450-F452. 25.

3. Río I, Castelló-Pastor A, Del Val Sandín-Vázquez M, Barona C, Jané M, Más R, Rebagliato M, Bolúmar F: Breastfeeding initiation in immigrant and nonimmigrant women in Spain. Eur J Clin Nutr 2011, 65:1345-1347.

4. Vohr BR, Poindexter BB, Dusick AM, McKinley LT, Higgins RD, Langer JC, Poole WK: Persistent beneficial effects of breast milk ingested in the neonatal intensive care unit on outcomes of extremely low birth weight infants at 30 months of age. Pediatrics 2007, 120:e953-e959.

5. Pineda R: Direct breast-feeding in the neonatal intensive care unit: is it important? J Perinatol 2011,31:540-545.

6. Maayan-Metzger A, Avivi S, Schushan-Eisen I, Kuint J: Human milk versus formula feeding among preterm infants: short-term outcomes. Am J Perinatol 2012, 29:121-126.

7. Fairbank L, O'Meara S, Renfrew MJ, Woolridge M, Sowden AJ, Lister-Sharp D: A systematic review to evaluate the effectiveness of interventions to promote the initiation of breastfeeding. Health Technol Assess 2000, 4(25):1-171.

8. Renfrew MJ, Craig D, Dyson L, McCormick F, Rice S, King SE, Misso K, Stenhouse E, Williams AF: Breastfeeding promotion for infants in neonatal units: a systematic review and economic analysis. Health Techol Assess 2009, 13(40):1-146.

doi:10.1186/1746-4358-7-22

Cite this article as: Río et al:: Uneven chances of breastfeeding in Spain. International Breastfeeding Journal 2012 7:22.

\section{Submit your next manuscript to BioMed Central and take full advantage of:}

- Convenient online submission

- Thorough peer review

- No space constraints or color figure charges

- Immediate publication on acceptance

- Inclusion in PubMed, CAS, Scopus and Google Scholar

- Research which is freely available for redistribution 